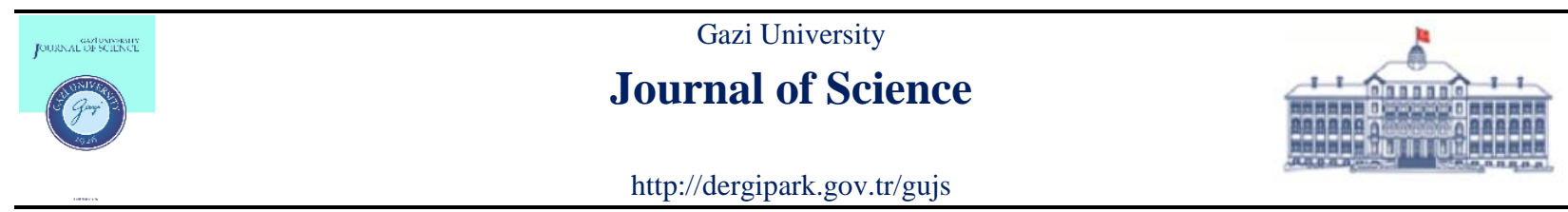

\title{
Review on Vehicle-to-Grid Systems: The Most Recent Trends and Smart Grid Interaction Technologies
}

\author{
Melih SARP ${ }^{1}$, Necmi ALTIN ${ }^{2 *}$ (i) \\ ${ }^{1}$ Gazi University, Graduate School of Natural and Applied Sciences, 06500 Ankara, Turkey \\ ${ }^{2}$ Gazi University, Faculty of Technology, 06500, Ankara, Turkey \\ Highlights \\ - Effects of the V2G system on the power quality has been explained. \\ - The integration of V2G systems with smart grid technologies has been addressed. \\ - The challenges on V2G infrastructure and technology, and communications issues are presented. \\ - The future of the V2G systems have been discussed.
}

\begin{tabular}{l} 
Article Info \\
\hline \\
Received: $15 / 04 / 2019$ \\
Accepted: $28 / 11 / 2019$ \\
Keywords \\
\hline Vehicle-to-grid (V2G) \\
systems, \\
Smart grid \\
Smart charging \\
Ancillary services \\
Power quality
\end{tabular}

\section{INTRODUCTION}

The present world is faced with the ever-growing problems of air pollution, fossil fuel depletion, climate change and constantly increasing energy costs, all of which can be tied back to a common cause - the use of conventional energy resources. There is an imminent need to reduce the amount of Greenhouse Gas (GHG) emissions leading to global warming and, accounting for about $23 \%$ of global GHG emissions, the transport sector holds a key role [1]. Electric vehicles (EVs) and related infrastructure may effectively counter these emission rates as they offer better energy efficiency and carbon intensity reduction for energy carriers, as well as support variable renewable energy options [2] In this review, an EV is defined as any vehicle that runs entirely or partially on electrical energy provided by a battery. Its ability to provide 'clean' energy to distribution grids and micro-grids (MGs) of the power system adds the appeal for further research in this area [3].

EVs as a primary mode of private transportation is becoming a global phenomenon as lower costs, extended vehicle range and resolution of other consumer issues have been made possible through government-backed policies. Members of the Electric Vehicles Initiative (EVI) forum (established in 2009 under the Clean Energy Ministerial (CEM)) continue the support for global adoption of EVs and are aiming to globally deploy 20 million electric cars by 2020 (CEM, 2016). As of 2015 several countries such as Norway, the Netherlands, Sweden, Denmark, France, China and the United Kingdom declared market shares of EVs to 
be above $1 \%$, with market shares reaching $23 \%$ in Norway and almost $10 \%$ in the Netherlands [4]. In 2015 China became the global leader in EV sales, with similar trends in e-scooter and electric bus sales as well [4]. Furthermore, the Paris Declaration on Electro-Mobility and Climate Change and Call to Action is also endorsing the shift toward EVs, including cars and 2-wheelers and 3-wheelers, setting a deployment target of 100 million and 200 million for these, respectively, by 2030 [5]. Such rapidly growing numbers of EVs could have severe impacts on the distribution grid in particular. Their need for charging creates an additional load for the grid. The V2G technology is introduced to transform these loads into new, controllable electric sources with power management strategies and smart grid facilities.

The basic concept of the $\mathrm{V} 2 \mathrm{G}$ is based on the delivering power from the battery of an electric vehicle to the grid at peak demand hours of power, enhancing the reliability of the system [6]. Electric vehicles can also be used as a storage device. A network of easily and readily accessible energy storage devices that are capable of supplying direct power flow to the distribution grid can be created with EVs. The transformation of these loads into new sources of electrical energy for the grid is made possible via their interaction with smart grids. Also, EVs operating within the V2G system provide another source of power to that produced by renewable sources such as wind and solar, by acting as depositories for excess energy produced by centralized renewable energy power plant [7]. The key components of a V2G system include the charging infrastructure, the aggregator, the independent system operator (ISO), renewable energy resources, the electric utility, the EV and its battery pack, unidirectional and bidirectional power flow and, ideally, smart metering and control systems [8].

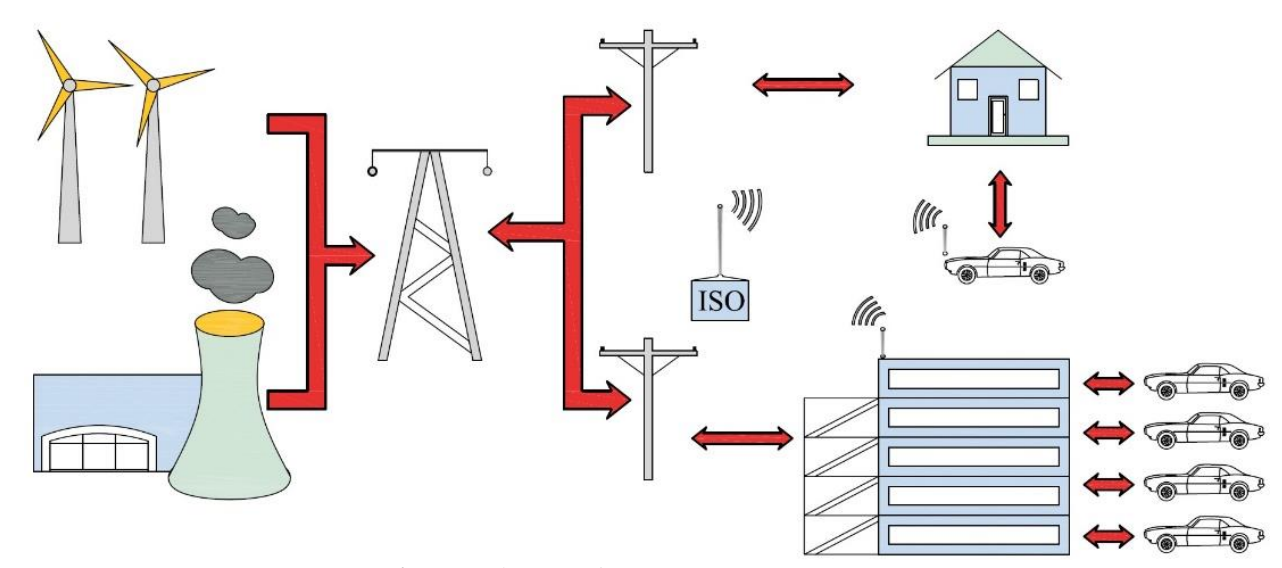

Figure 1. A schematic of V2G Setup

Figure 1 represents the V2G setup. In this figure, the flow of electricity from one component of the system to the other is as follows: one-way flow from the generator to the electricity user, one-way flow from the EV to the grid or bi-directional flow between batteries of EVs and the grid. The control signal from the ISO or grid operator, which translates as a request for power from a large number of vehicles, could be in the form of a radio signal, a signal sent through a cell phone network, a direct internet connection or a signal transmitted through a power line carrier. Figure 1 depicts how such a signal may reach each vehicle individually directly (upper right) or how a fleet operator can mediate for a fleet of vehicles. By using combined on/off charging signals, the independent system operator can manage a fleet of EVs in order to provide a reserve for compensating renewable power generation variability.

Since the V2G is a promising concept, different review studies on V2G systems have been published [6], [9-16]. Some studies focused on the impacts of the V2G systems on the power system and distribution grid. Whereas, [11] focused on the impacts of the V2G system on the power system stability, authors focused on the impacts of charging on distribution grid and battery degradation in [6] and [12]. The advantages of the V2G systems are presented in another review study [15]. However, main focus of the study is the optimization of V2G algorithms. It is mentioned that optimization techniques are kind of mandatory part of the system to handle the increased power system complexity with the dynamic and random behaviors of EV mobility [12]. In [12] and [9], the current status of battery chargers, charging power levels, and infrastructure for EVs are investigated and reviewed. Different power converter topologies with the corresponding charge levels have been presented. In [16], a review study on integration of renewable energy 
sources and V2G systems have been presented. The PV and wind system integration with a V2G system is investigated. Authors also briefly explain the smart metering and smart charging. Since the charging and discharging of the EV battery has nonlinear characteristics, well-known measurements methods cannot be applied directly. Therefore, power measurement methods have been reviewed in [10]. In [13] and [14], the challenges of the V2G systems presented briefly. The battery degradation, energy management and optimal coordination are highlighted as major challenges. However, any solution has not been proposed. As can be seen above, most of these review studies just focused on a piece of a V2G system or impacts of it. A study, studying this subject as a system is missing. In addition, the concept goal of the smart grid, another promising and attractive topic, along with the future deployment of the EVs poses several challenges on terms of electric grid infrastructure, communication and control that need to be addressed before the electric grids are established and EVs are deployed on mass. Furthermore, system stability, reliability, efficiency and losses also pose concerns for $\mathrm{V} 2 \mathrm{G}$ systems. The main objective of this paper is to present a comprehensive review of latest solutions relating to these issues. This review delves deeper to discuss power management strategies and the various effects of the V2G system on power quality, the smart grid solutions like smart charging and smart communication and the ways in which smart parking lots may provide solutions for the problems of the power grid. Besides, a discussion on the integration of EVs to MGs via the V2G system is covered. Finally, the future of the V2G systems is evaluated. Rest of the paper is organized as follows: Section II provides an overview of power management strategies for the V2G system and power quality solutions, and smart grid solutions which can be implemented to V2G system are discussed in section III. The MG concept with V2G system is discussed in section IV. Section V shares our perspectives on future trends in this field, and section VI is the conclusion.

\section{POWER MANAGEMENT STRATEGIES FOR V2G SYSTEM}

The flow of power, either unidirectional or bidirectional, between the EV battery and power grid is controlled and managed by the power grid operator of the aggregator. Such management of the V2G system aims to maximize the profit, to reduce emissions and to improve the power quality of the grid $[15,17]$. With unidirectional V2G technology, the charging rate of the EV battery is controlled through a one-way flow of power between the EV and the grid [15]. Unidirectional V2G is inexpensive when a simple controller is used to manage the charge rate. It can provide ancillary services such as grid regulations and spinning reserve to the power grid [18]. Unidirectional V2G services are, however, unable to provide peak load shaving, reactive power support, voltage regulation and frequency regulation services that are provided only by bidirectional V2G systems. Bidirectional V2G systems have a two-way power flow capacity between an EV and the power grid [19]. It has several benefits including active and reactive power support, power factor regulation and also a renewable resource integration capacity $[20,21]$. These services are based on the ability of bidirectional systems to charge EVs during off-peak hours and supply power to the grid during peak hours which is achieved through the use of an appropriate charger DC link capacitor in combination with proper control switching [22].

A typical bidirectional EV battery charger is composed of an AC/DC converter and DC/DC converter [23]. The AC/DC converter rectifies the power grid $\mathrm{AC}$ power to $\mathrm{DC}$ power during charging and inverts the $\mathrm{DC}$ power to $\mathrm{AC}$ power before it is sent back to the power grid during discharging. The DC/DC converter uses a current control technique when acting like a buck or boost converter during charge or discharge modes [23].

The search for bidirectional flow charger structures for the V2G system is still ongoing. AC/DC converters that are used for this purpose are typically H-bridge-based converters such as single-phase half-bridge, single-phase full-bridge, and three-phase full-bridge converters and high-power systems generally require multilevel topologies [10]. There is also ongoing research into devices which can achieve more efficient AC/DC converter structures with wide-bandgap semiconductor devices. Recent studies on Silicon Carbide $(\mathrm{SiC})$ and Gallium Nitride $(\mathrm{GaN})$ semiconductor devices have shown that these devices provide higher blocking voltages, higher switching frequencies, and higher junction temperatures than silicon devices. These features enable high efficiency, high power density power electronics converter designs. It is reported that 97 99\% efficiencies can be achieved with $\mathrm{SiC}$ devices in the AC/DC converter [24, 25]. 
The bidirectional DC/DC stage is known to have a direct impact on the overall efficiency and size of the system. The primary aim of current research is based on discovering methods in which soft-switching in power switches for a wide range of load variation is possible such that electromagnetic interference (EMI) is avoided and very high-frequency operation is enabled, thereby reducing the costs and size implications related to the magnetics and output filter.

Dual active bridge converters and resonant converters have thus gained popularity in DC/DC applications in EVs. [25-29] Their main topologies are shown in Figure 2. The researchers propose different DC/DC converter topologies derived from these two main topologies. One study has presented a series resonant matrix converter-based battery charging topology capable of bidirectional power flow and DC fast charging for high power EV batteries [27]. This topology is based on soft-switching techniques and can perform V2G power transfer. The PWM resonant converter (PWM-RC) has also been suggested as an alternative to the isolated/bidirectional DC/DC converter in the on-board charger of EVs [25]. Despite having good switching characteristics, the main disadvantage of PWM-RC is the 'buck type' operational requirement, making it unsuitable for bidirectional applications. The structure change method is therefore employed to overcome this characteristic gain issue. The CLLLC-type resonant converter has been proposed in another study [26] which demonstrates how soft-switching in all switches can be ensured without additional snubber or clamp circuitry. This capacity enables very high-frequency operation thus allowing smaller magnetics and filter capacitors to be used.

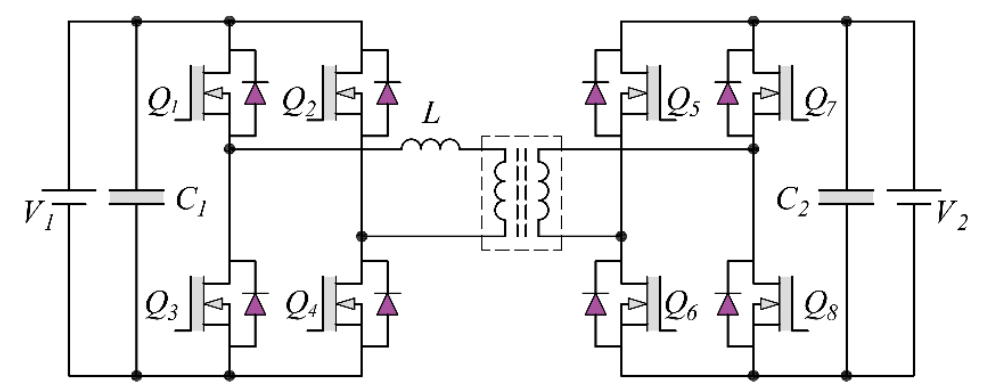

(a)

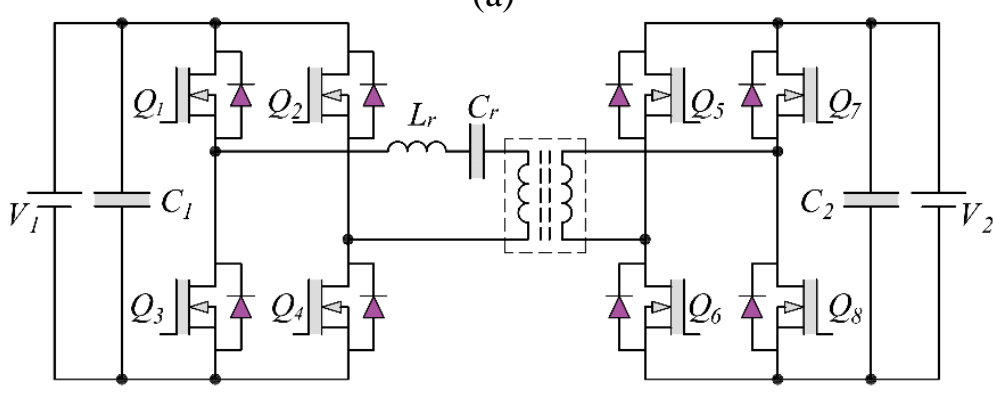

(b)

Figure 2. a) Dual active bridge converter topology and b) Series resonant converter topology

Another type of topology for bidirectional operation, dual-active-bridge (DAB) converters, has also been widely used in industry as they have a buck/boost type operation, high power capability and can accommodate a wide range of voltage levels. It does, however, have large reactive current flows which both lead to an increase in power losses and creates electrical stress on its switching elements [29]. Several control methods and the application of semiconductor devices have been proposed as solutions to these limitations and as a means to improving efficiency [30-32]. A unified high-frequency AC buck/boost (UHFBB) control strategy for dual-active-bridge bidirectional converter (DAB-BDC) is proposed as a means of achieving optimized current stress of switches and soft switching in a broader range whereby the buffering inductor current is operated in discontinuous conduction mode (DCM) or boundary conduction mode (BCM), resulting in the ZCS of switches as well as high efficiency [31]. Furthermore, the effectiveness of a multi-variable solving method for achieving duty ratios for driven signals modulation has also been verified. 
Control of the charger output current is an important issue with regards to the charging and discharging process of lithium-ion and other types of batteries [33]. A new topology based on AC-DC Dual-ActiveBridge is proposed as a control mechanism that can counter the problem associated with measuring the averaging current at the charger output. The bandwidth achieved by the controller is increased by incorporating a Smith Predictor (SP) in the feedback loop which compensates the delay time associated with the measurement. It has been demonstrated that the limited bandwidth of the current control loop caused by measurements averaging can be overcome [33].

Achieving high efficiency has been based on applying the variable modulation strategy for a DAB converter with a wide operating range in another study as well where the method proposed involves the automatic change of four modulation strategies for efficiency optimization under the operating voltage and the output power [31]. The study reports that a $98.9 \%$ efficiency was achieved by applying the method for a $3 \mathrm{~kW}$ DAB.

The inevitable impact of EV battery chargers on the distribution system will ultimately lead problems regarding power quality (PQ). The harmonic currents introduced into the distribution system due to the high ratings and nonlinear switching devices used by these chargers require a form of correction so that the performance and safety of other equipment connected to the power system are not compromised. There have been several efforts towards balancing optimal bidirectional charger topology against the power quality problems inherently created by these systems. [34]. One study proposed a bidirectional EV charger composed of a VSI AC/DC converter and a DAB DC/DC converter in which the charger topology disclosed has an ability to act as a shunt active power filter while the battery injects power in the home. Whilst the shunt active power filter greatly reduces the current harmonics and thus in effect the grid current THD (Total Harmonic Distortion), the DC/AC converter provides a unity power factor to the grid whilst also regulating the DC link voltage. However, there is a lack of discussion on voltage unbalance particularly in regard to the active filtering operation. Other studies [35, 36] have proposed a bidirectional grid interface capable of both acting as an active power filter and battery, thereby providing correction of harmonic currents and compensating reactive power in single-phase electricity networks.

The larger the number of EVs connected to the power system, the more likely the issues created with such loads are to be encountered. Such problems and limitations may be related to charging costs, Greenhouse Gas (GHG) emissions or losses in the power system and will vary in nature depending on the primary usage objectives of the EV system. Problems that may arise from uncertainties related to load demand on the distribution network operation must have pre-formulated solutions to minimize any potential impacts on the system. In [37] the combination of new stochastic power flow based on unscented transform and a new Bat Algorithm (BA) based optimization algorithm was tested in a grid-connected local distribution system. The study proposes the combination as a solution to countering the uncertainties caused by both renewable energy-based power sources and charging/discharging pattern of EVs. One study suggests methods for reducing the probability of line congestions and voltage violations in smart grids located in the radial distribution network. The authors take into account power demand, the power generated by wind and solar photovoltaic generators, and the behavior of the EVs that do not participate in the congestion procedure to propose a probabilistic model based on renewable distributed resources and high penetration of EVs [38]. Another study [39] utilizes data such as the EV owner's behavior and EV market details data to demonstrate how the power system demand profile, the operation stability index and reliability indices are affected by the power exchange between the grid and EVs. The EVs themselves may improve grid power quality by lending the energy stored on-board to compensation devices like Dynamic Voltage Restorers (DVRs) (for voltage dip compensation) and Static Synchronous Compensators (STATCOMs) (for voltage regulation and reactive power control) and preventing disturbances commonly caused within the grid [40].

Although the V2G system promises to reduce the intermittency of renewable energy on electric power grids, its impact on the vehicle battery should be considered. The depth of discharge, the amount of power drawn and the cycling frequency are essential factors that cause battery degradation. There are a few studies investigating the grid impact on EV batteries [41, 42]. The V2G system will cause more usage of the battery cells and it is important to understand the impact of bidirectional charging on batteries in order to evaluate their viability as a grid support service. In [42], the effect of bidirectional charging on Li-on cells used in 
electric vehicles is studied. The result shows that the increase in cycling frequency at constant power deteriorates the battery performance.

\section{SMART GRID SOLUTIONS FOR THE V2G SYSTEM}

The smart grid integrates communications, smart energy metering and advanced control technologies and presents the power industry with EVs as distributed and deployable energy sources with much potential and several advantages. The grid operator or aggregator and the EV are able to communicate with each other through the EV management system. This management system may employ a smart meter (SM) for facilitating real-time energy measurement, communication with and control of EVs. Furthermore, the bidirectional power flow between the EV and the grid can be used to implement smart scheduling to optimize the available grid power.

The general operational layout of the smart grid - charging system communications setup has successfully represented by Amoroso et al [42] as shown in Figure 3. The grid supervisor will dispatch energy from the grid to a given number of EVs based on the communications between the grid and the smart charging system which may be achieved through either power line communications or wireless systems. A charge monitor plays a crucial role in determining the battery state of charge and operating conditions in a smart charging system. The charge monitor relays this information to the core controller to which it is connected and the core controller then sets a charging rate for a particular vehicle depending on number of factors such as initial state of charge, amount of energy required, preferences of the user, the present schedule of the system, the specifications of the system and the pricing of the electric utility [43].

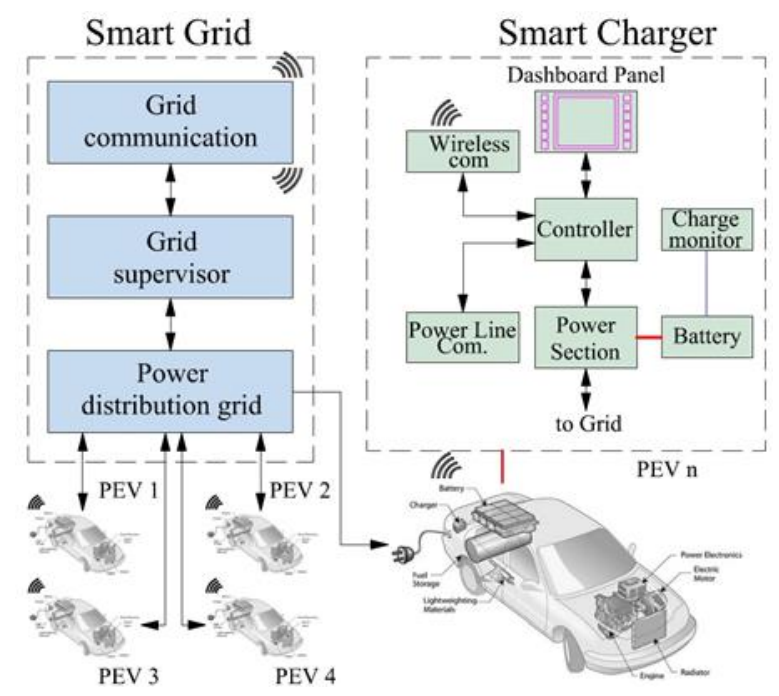

Figure 3. The general operational layout of the smart grid - charging system communications setup

In order to effectively implement a V2G system with smart grid facilities, a standardization system is necessary. Standardization applies to a range of V2G areas including charge coupling, communication protocols and safety. Table 1 summarizes the relevant European and US standards for the charging interface. 
Table 1. Relevant Standards for the Charging Interface (Europe and US)

\begin{tabular}{|l|l|l|l|l|}
\hline Connector & Communication & $\begin{array}{l}\text { Charging } \\
\text { Technology }\end{array}$ & Safety & Interoperability \\
\hline IEC- 62196-1 & IEEE 80211P & IEEE P2030.1 & IEC 60529 & SAE J2953/1 \\
\hline IEC- 62196-2 & IEC 61850 & IEEE P2030.2 & IEC 60364-7-722 & SAE J2953/2 \\
\hline IEC- 62196-3 & IEC 61851-24 & IEEE P2030.3 & ISO 6469-3 & \\
\hline SAE J1772 & ISO/IEC 15118 & IEEE P1547.1 & ISO 17409 & \\
\hline & SAE J2847/1 & IEEE P1547.2 & SAE J1766 & \\
\hline & SAE J2847/2 & IEEE P1547.3 & SAE J2344 & \\
\hline & SAE J2847/3 & IEEE P1901.2 & SAE J2929 & \\
\hline & SAE J2847/4 & IEC 61851-1 & SAE J2578 & \\
\hline & SAE J2847/5 & IEC 61851-21 & SAE J2464 & \\
\hline & SAE J2847/6 & IEC 61851-22 & SAE J2380 & \\
\hline & SAE J2931/1 & IEC 61851-23 & & \\
\hline & SAE J2931/2 & SAE J2836/1 & & \\
\hline & SAE J2931/3 & SAE J2836/2 & & \\
\hline & SAE J2931/4 & SAE J2836/3 & & \\
\hline & SAE J2931/5 & SAE J2836/4 & & \\
\hline & SAE J2931/6 & SAE J2836/5 & & \\
\hline & SAE J2931/7 & SAE J2836/6 & & \\
\hline & & & & \\
\hline & & & & \\
\hline & &
\end{tabular}

\subsection{Smart Charging Solutions}

Smart grids, despite the associated system requirements that come with it, currently present the best strategy for smart charging management. Smart-charging schemes may be employed for several reasons including the minimization of system or charging costs for the electricity market (which generally results in a valleyfilling charging scheme), or they may simply aim to address or prevent known impacts on the electrical grid network. The power grid faces many challenges, as well as opportunities, in the face of large-scale EV adoption. One challenge is in the fact that charging patterns are inherently unpredictable which is a potential problem if smart charging techniques are not employed. On the other hand, the successful use of intelligent scheduling EV charging/discharging activity management presents a real opportunity for integrating electrical and transportation systems. Recently, control and monitoring of the electrical grid connected to EV batteries with intelligent smart grid solutions have been studied. Intelligent controllers such as the fuzzy load controller and the fuzzy voltage controller used in the V2G systems are able to achieve a balance between grid power generation and grid load through load leveling, voltage regulation, balance and the supply of peak power, thereby optimizing grid efficiency [44]. A real-time smart charging station coupled with fuzzy logic controller for charging and discharging of EVs is presented in [45]. Besides, the integration of renewable energy resources into these charging stations is both environmentally-friendly and offers support to grid operations. A smart control algorithm for system component coordination has been proposed in photovoltaic and EV battery setups for the management of peak loads and domestic power quality in a system [46]. It has been shown that such strategic management of battery storage in households with the photovoltaic and V2G setups is capable of shaving up to $37 \%$ of peak loading on the electricity distribution grid [46]. The use of model predictive control (MPC) for robust frequency control design of an isolated small power system utilizing a photovoltaic power source was proposed and the system was tested against variable changes in load and inconstant renewable (photovoltaic) power. The results of the simulation showed that the proposed MPC-V2G controller remained robust against step load changes, variable load changes and inconstant renewable power (photovoltaic) sources. PV power imbalances or uncertainty is a major concern with regards to optimizing V2G capacities and methods such as the particle swarm optimization (PSO)-based Monte Carlo simulation have been proposed to connect scheduled output to actual power, thereby reduce any associated penalty costs and increasing revenue and incentives for both PV producers and EV owners [47].

EV infrastructure planning is essential for meeting charging demands and developing a financial strategy against installation and operation costs for both the EV charging infrastructure and the power grid. Utilizing 
the energy internet (renewable energy is the main energy unit, energy supply and transmission networks/technologies are coupled and real-time energy and information flow is monitored through internet/information technology [48, 49]) will facilitate the control of EV smart charging networks and ultimately bring economic benefits to stakeholders. [50]. One study explains how this can be realized [50]. Authors propose methods and business models to integrate existing hardware platforms and propositions for the construction of EV smart charging networks that will be coupled with energy internet usage. Another study discusses the use of energy routers with energy internet, as they can technically support EV involvement in the direct energy transaction and power demand response [49]. The study considers three scenarios, namely, V2G, V2H (Vehicle-to-home) and V2V (Vehicle-to-vehicle), to provide an optimal model for smart charging/discharging using an energy router, as a means of increasing user benefits and reducing peak-valley difference rates in the power system.

\subsection{Smart Communication Solutions}

Smart grids, integrated into the V2G system for the intelligent management of power provision to consumers, work off the advanced communication technologies capable of consolidating data from various system components in a manner that maintains system sustainability [51]. Communication technologies allow for the bidirectional interaction between the utility and the customers, maximizing interoperability [52] and the ability to control this energy exchange increases the feasibility of the implementing the V2G concept [51]. The bidirectional communication is essential for checking battery conditions and relaying instructions [8]. Each EV in a fleet needs to achieve data exchange with both the grid operator and the aggregator. Such basic data may include vehicle ID, vehicle preferences or constraints, battery storage capabilities, battery state-of-charge and power flows requests/demands between the battery and grid. More critical issues related to V2G systems include the range, cost, reliability and security of the communication systems involved [53].

The information exchange between EV and the smart grid may occur in various ways depending on the particular location and connection capabilities of the EV. EVs which are charging at a charging point or at home must utilize a telecommunication solution that fulfills the ISO/IEC15118 standard requirements. EVs connected at home may also use wireless networks resources. Home Area Network (HAN) communication services features should comprise relatively low data rate $(<1 \mathrm{Mbps})$; high reliability, low latency, low power consumption, medium-range coverage area and secure communication in order to provide adequate and acceptable means of connection.

Other options such as wireless networks and cellular communication systems should be considered for EVs that are connected elsewhere or traveling in locations without suitable communication infrastructures as they allow mobility, have low installation cost, are capable of rapid deployment and offer extended coverage over traditional wired solutions. For this, accessibility to several radio access technologies standards such as: 2G/3G/4G cellular networks; IEEE 802.16 WiMAX and IEEE $802.11 \mathrm{~b} / \mathrm{g} / \mathrm{n}$ wireless LAN is required. Wireless communications in highly mobile V2G environment do, however, also pose challenges, such as reliability and real-time communication. One such challenge involves smart metering capabilities and the issue of having the EV connected to a different aggregator, energy supplier or visiting network when it is not connected to its HAN or LAN. Reliability over a large area of connection thus also becomes an issue [16].

Several different wireless communication solutions are available for V2G systems as displayed in Table 2 [54]. The WiMAX protocol covers communication between the aggregator, the energy market and the utility and therefore represents a long-distance communication scenario. GPS or/and Bluetooth-enabled functionalities allow the common smart mobile phone to as an interface between the EV managing system, the charging point and the aggregator. The Near Field Communication (NFC) protocol can be used to support Bluetooth pairing and reduce more than eight user interactions to establish Bluetooth connection, thereby acting as a means of increasing reliability in the smart grid system. Amongst these ZigBee is, a low power, low cost and low complexity communication protocol based on IEEE 802.15.4. Enabling capacities such as automatic control and industrial automation and monitoring, ZigBee is used for communication between various network entities [54]. It provides an application layer standard for energy usage regarding 
communications about efficiency, cost and messaging [55]. One study proposed a smart metering system based on the ZigBee network where the bidirectional communication feature of the system allows the submeter to update the smart metering system parameters to the host, receives pricing commands and can be remotely controlled. [56]. Another study presents a control charging management system comprised of a single-node charging controller and a centralized management system. [57] Centralized control is based on the ability of the smart charging management system to receive and transmit data regarding charging via ZigBee and GPRS wireless communication networks technology.

Table 2. Wireless communication technologies for V2G applications [54]

\begin{tabular}{|l|l|l|l|}
\hline S/N & Technology & Operating frequency & Covered Distance \\
\hline 1 & ZigBee & $\begin{array}{l}868 \mathrm{MHz} \text { (Europe) } \\
915 \mathrm{MHz} \text { (North America) } \\
2.4 \mathrm{GHz} \text { (Worldwide) }\end{array}$ & $10-100 \mathrm{~m}$ \\
\hline 2 & $\begin{array}{l}\text { Near Field Communication } \\
\text { (NFC) }\end{array}$ & $13.56 \mathrm{MHz}$ & $5-10 \mathrm{~cm}$ \\
\hline 3 & Bluetooth & $2.4 \mathrm{Ghz}$ & $1-100 \mathrm{~m}$ \\
\hline 4 & IEEE 802.11p & $5.85-5.925 \mathrm{Ghz}$ & $500-1000 \mathrm{~m}$ \\
\hline 5 & WIMAX & $2-6 \mathrm{GHz}$ & $2-5 \mathrm{~km}$ \\
\hline
\end{tabular}

The V2G network communication systems are, however, different from broadly applied communication systems which are capable of not only facilitating functionalities for data and power delivery, but also prone to cyber-physical attacks. The issue of security and privacy is much more problematic for the highly distributed V2G networks and consequences are accordingly more severe. [58,59] is just one work among the many studies that have focused on privacy preservation for EVs in V2G systems. This method for achieving this involves the use of a "permit" generated by the ID-based restrictive partially blind signature technique, which protects the location privacy and ID of EV owners. One work [60] proposes a bilinear pairing technique in which an accumulator provides mutual authentication, and thus enables the preservation of private information of EV's such as identity, battery status, location, and charging/discharging selection and time duration. Issues relating to V2G communications dynamics and security have been covered in another study [61] which proposes the use of software-defined network (SDN) technology, a novel security communication mechanism (SCM) for the dynamic V2G system. In [62], an anonymous payment system is described. This system is capable of both allowing location privacy as well as allowing the traceability of stolen vehicles by means of appointing a judge who can open all transactions in the case of any dispute consent from the user. With the user's consent (kept as secret information) the judge may investigate and track any transaction, past or future, of a user, while also being able to keep the transactions from other users unopened. Another discussion is related to the risks posed to user privacy by $\mathrm{V} 2 \mathrm{G}$ networks which are based on the transfer of direct, unencrypted information from PHEV batteries to the system controller [63]. The researchers [63] focused on developing designs for V2G systems, which allow for privacy through distributed processing and cryptographic security. One group developed a set of interlinked subprotocols which take into account the different security and privacy concerns of the various EV-power grid interaction types, which may be in form of 'energy demand' (i.e., a customer), 'energy storage' or 'energy supply (i.e., a generator) [64]. In the role-dependent privacy preservation scheme (ROPS), the group demonstrates how the various subprotocols can cater to different privacy considerations when an EV acts as a customer, storage, or a generator.

\subsection{Smart Parking Solutions}

It will be smart parking lots incorporated into the power system, equipped with V2G technologies, communication and other intelligent devices for EVs that will contribute to the faster uptake of the V2G concept. Large fleets are much more easily managed by the system [61] and therefore large parking systems, capable of supporting communications and intelligent devices, form an essential part of the total required infrastructure [65].

In fact, smart parking lots further promote the V2G concept by enabling faster charging with high levels of power. However, charging is primarily affected by EV owner behaviors, which remain unpredictable to a 
large extent. As such, parking lots, with the parking rules and regulations with which they operate, help with managing the variations in customer behaviors [66]. A representative schematic of a typical parking lot setup has been given in Figure 4 [67].

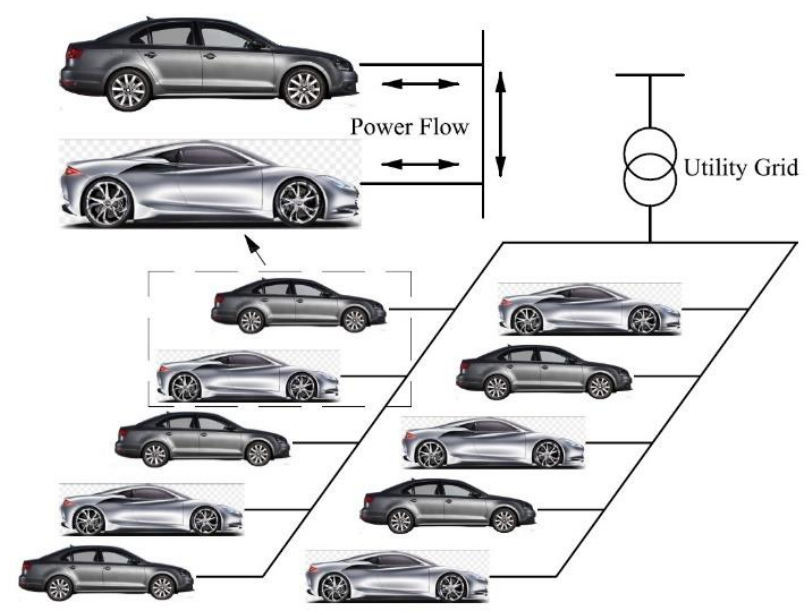

Figure 4. A representative schematic of a typical parking lot setup

When cars are not used during the day, which is typically quite a long period of time, they may be recharged at parking lots [68]. The utilization of parking lots as charging stations can be optimized through the application of a recharge scheduling system so that the behaviors of and supply to both regular and irregular users can be tracked and managed. A successful model for optimal scheduling and energy management, which integrates system variables such as charging electricity price, remaining battery capacity, remaining charging time, and battery age has been proposed previously [53]. The results show that the proposed parking lot energy management system satisfies both financial and technical goals. Moreover, EV owners could earn profit from discharging their vehicles as well as having desired SOC (state of charge) in the departure time. A model for controlling the charging/discharging activity of a large number of EVs based on system constraints and customer preferences is proposed as a means of EV energy management for an intelligent parking lot. The results presented are successful from both a financial and technical perspective. [53].

\section{MICROGRID WITH V2G SYSTEMS}

The MG is a medium voltage or low voltage power grid, which can work both grid-connected and islanded mode. It is mainly composed of distributed generators, storage systems and controllable and/or critical loads. Energy Storage Systems (ESSs) is essential for ensuring the quality of energy supply as it compensates for the imbalances between generation and load in MGs (island/isolated mode of operation) by providing then necessary power during imbalances or disturbances. ESS also accounts for the intermittency of renewable energy sources and allows them to operate as additional power units that dispatch energy upon request [69]. In this sense, EV batteries can also act as ESS for MGs as they can store off-peak energy produced and offer this back either to the EV or the MG. They may even operate together with other ESSs, providing better power quality $[7,16,70]$.

V2G technology can be an effective solution to utilize EV batteries for renewable energy resources. There are many studies which aim to solve problems related to MGs and improve its efficiency with V2G techniques. For MGs to be able to supply the demanded charge, EV charging demands must be effectively managed and strategized. Various control strategies and optimization procedures have been proposed for managing the dichotomous relationship of EVs and electric systems - EVs can act as controllable loads or distributed ESSs [71]. A strategy for such energy management of EV-renewable MG systems have been previously proposed [72]. The study describes a smart charging strategy applied to public charging stations and residential communities, with which cost function value reduction will be able to support larger EV penetration. Adverse results such as loss of peak-load hours and increased MG costs were implied without the proposed strategy. In one study [71] an EV control strategy developed for defining the daily 
charging/discharging activity of each EV in an MG was proposed and verified through a simulation involving the connection of two MG clusters through an EV operating in V2G mode. Another study presents a novel chance-constrained programming model for the management of a renewable MG-V2G storage system. [73], the authors state that through the use of the Metropolis-Hastings algorithm (a Markov chain Monte Carlo Method), plug-in patterns can be estimated, saving substantial costs for the MG when the V2G is integrated. In another study, real data was used for the Sample Average Approximation (SAA) Monte Carlo simulation in which they tested their proposed optimization method for managing a solarpowered MG with building loads, battery ESS and EVs, with which both intermittencies of solar generation, loads and EV profiles could simultaneously be accounted for [74].

Uncertainties related to parking decks, such as the variable number of $\mathrm{V} 2 \mathrm{G}$ stations installed and the number of EVs available, which in turns causes concerns regarding project investments [71, 74]. Optimal ESS power and energy capacities must be found in order to accurately size the storage system, in effect also reducing operational costs of the MG [75]. This attempt was undertaken in [74] where the variable storage capacity of the parking deck (and thus the number of charging stations required) was determined using an inhomogeneous continuous-time Markov chain and Monte Carlo simulation to model the uncertainties. The 5-year experimental results of the simulated 14-bus distribution system revealed reduced operational costs for electricity supply in the long term, thus supporting V2G investment.

In the autonomous MG, differences between power generation and demand caused by intermittent (renewable) energy sources lead to frequency fluctuations when RES and EVs are not coordinated. Coordination of RES and EVs, referred to as load frequency control (LFC), may be insufficient in some MGs, and proposals for improving LFC response to increase frequency stability have previously been reported $[76,77]$. V2G power control can also be used as a strategy, especially in the island operation mode of MGs as shown in [77]. The authors present a high precision controller tracking frequency and the performance of the propose LFC is evaluated through hardware-in-the-loop simulations and using real wind and solar radiation data. In another study, actual power generation, baseload, peak load, EV aggregator and various renewable energy sources were used, with different residential loads and EV numbers, to show superior V2G-based frequency regulation in island grid modes of MGs [78].

In addition to using EVs as mobile storage units in the V2G system, the use of robust and adaptive controllers operable over a wide range of system operating conditions is necessary overcoming the limitations of LFC in an isolated MG [79]. Combining general type-2 fuzzy logic sets (GT2FLS) and the Modified Harmony Search Algorithm (MHSA) technique as a means of tuning the proportional-integral (PI) controller for LFC in islanded MGs, and thereby effectively regulating MG frequency, was shown to be a feasible approach [79].

\section{THE FUTURE OF THE V2G SYSTEM}

The future appears to hold much promise for EVs and related technologies based on the many advantages and benefits they hold compared to current, conventional transportation. EVs and the V2G system offer a host of ancillary services such as load leveling, load regulation and energy reserves. However, along with these advantages, a number of challenges come that need to be overcome before the full potential of EVs may be realized. Perhaps the most obvious of these challenges is effective management of the establishment of infrastructure, costs and the actual impact on the power system.

William Kempton at the University of Delaware and EV pioneer Tom Gage who have carried out the initial studies on V2G systems are continuing to run studies, which demonstrate the feasibility of the V2G concept. One such study involves the lease of a small number of BMW Mini-E EVs to users in an attempt to both track driving patterns and test grid regulation programs [80]. In the wake of the recent earthquake disaster in Japan, many people were left without any power. This event has inspired Nissan to create a vehicle-tohome (V2H) energy storage system where household energy consumption can be compensated by EVs. The Nissan Leaf's $24 \mathrm{kWh}$ battery was shown to be able to provide power to a household for close to 2 days [81]. Similar studies have been conducted in the U.S. in an attempt to create emergency power supply 
sources for U.S. homes [82]. Such prospects make EV ownership increasingly attractive along with improving grid regulation regimes and the potential for additional revenue generation.

Future trends for EV technology also include the improvement of charging times. Currently, fast charging involves 15-30 minutes of charging time to achieve $80 \%$ of the total charge capacity of an EV battery. Compared to the internal combustion engine (ICE) vehicles, fueling times are currently longer but efforts to achieve charging times as little as 5 minutes are also currently underway [83]. Faster charging times also translates to the increased feasibility of V2G related frequency regulation services. The revenue from frequency regulation services is expected to reach over $\$ 190.7$ million globally by 2022 , beginning with North America [7].

Other ancillary services to be provided by $\mathrm{V} 2 \mathrm{G}$ systems are expected to add to the revenue generated by the system until market saturation is reached. A comparison of the Texas power system G2V and V2G ancillary services market has revealed that bidding capacities are capable of causing a $70 \%$ reduction of the ancillary services market price in both systems with even just 300,000 and 100,000 EVs in each, respectively, signifying the speed at which market saturation could be reached [84]. This is a larger potential drawback for the V2G system it is more expensive to set up initially and market saturation may be reached before costs are reimbursed. As such, other services may need to be provided by the V2G to ensure economic gain from the system.

Completely successful V2G bidirectional power flow capacities are not expected to be achieved in the near future due to the issues related to communication security, amount of potential income offered to users, wear of EV batteries and the need for more, smarter infrastructure. To benefit from the bidirectional power flow capacity of V2G systems, further research and development, along with viable solutions, needs to be completed in these areas.

The establishment, operation and development of the V2G system will be driven by the amount of investment provided by stakeholders, the specific regional circumstances and the prices determined for ancillary and other services. Policy actions may be necessary in some cases to gather the required investments from either the relevant participants or from renewable energy generation systems integrated with the grid.

The future of the $\mathrm{V} 2 \mathrm{G}$ and the smart grid technology remains controversial to date although advancements in these areas are continuously being achieved. However, it would be acceptable to say that although fully functional, large-scale V2G systems are not to be in widespread use in the near future, the developments in the sub-fields of the system are worth to following and supporting.

\section{CONCLUSION}

The many different aspects to $\mathrm{V} 2 \mathrm{G}$ technologies were reviewed in this paper. Recent understandings of power management strategies for the $\mathrm{V} 2 \mathrm{G}$ system has also been covered here as the need for grid power optimization methods remains a primary concern for the $\mathrm{V} 2 \mathrm{G}$ concept. The integration of $\mathrm{V} 2 \mathrm{G}$ systems with smart grid technologies and MGs has also been highlighted to provide an understanding of the usage and advantages of such setups, with examples from recent projects. There is a growing awareness for the need to address not only challenges relating to V2G infrastructure and technology but also communications issues such as EV user privacy and security which present new implications for the user and the rate of uptake EVs. As such, we have further aimed to provide in this review some insight into the specific concerns and potential solutions discussed in this particular area.

The V2G concept presents an ideal functioning system with which EVs may be supported, monitored and utilized. The adoption of EVs improves and holds greater appeal for users when strategies to improve the efficiency, stability, reliability and power distribution with the V2G concept have been confidently established and implemented. The V2G implementation in conjunction with smart grid technologies holds much promise for the management of EVs, the grid of which they will work off and exchange between these two key elements. There are many issues currently impeding the widespread adoption of electric 
vehicles and the implementation of such complementary systems. However, the rapid and significant leaps in relevant technologies bring us ever closer to achieving this scenario. The discussion of the current progress intends to provide direction for future research and synergize the efforts of experts in this area.

\section{CONFLICTS OF INTEREST}

No conflict of interest was declared by the authors.

\section{REFERENCES}

[1] IEA, (2015b), "World energy balances", World Energy Statistics and Balances 2015, [Online], Available: http//:www.iea.org/statistics.

[2] Zidan, A., Gabbar, H.A., "Smart Energy Grid Engineering", In: Hossam A. Gabbar, editors. Design and control of V2G, Canada:Academic Press, pp.187-205, (2017).

[3] Aluisio, B., Conserva, A., Dicorato, M., Forte, G., Trovato, M., " Optimal operation planning of V2G-equipped Microgrid in the presence of EV aggregator", Electric Power Systems Research, 152:295, (2017).

[4] IEA, "Global EV Outlook 2016", Int. Energy Agency, pp. 52, 2016.

[5] UNFCCC (2015b), "Paris Declaration on Electro-Mobility and Climate Change and Call to Action", [Online]. Available: http://newsroom.unfccc.int/lpaa/transport/the-paris-declaration-onelectro-mobility-andclimate-change-and-call-to-action.

[6] Habib, S., Kamran, M., "A novel vehicle-to-grid technology with constraint analysis-a review", Proceedings of The International Conference on Emerging Technologies (ICET) (2014).

[7] Lehtola, T., Zahedi, A., "Sustainable energy supply using renewable sources supported by storage technology" Proceedings of The IEEE Innovative Smart Grid Technologies - Asia (ISGT-Asia) :71, (2016).

[8] Tuttle, D. P., Baldick, R., "The Evolution of Plug-In Electric Vehicle-Grid Interactions", IEEE Transactions on Smart Grid, 3(1):500, (2012).

[9] Sharmaa, A., Sharmab, S., "Review of power electronics in vehicle-to-grid systems", Journal of Energy Storage, 21:337, (2019).

[10] J. R. Cui, J. Y. Zhou, Z. Xu, Z.W. Zhang and Q. Li, "Review of active power measuring methods for Vehicle-To-Grid (V2G)", Proceedings of The IEEE Chinese Automation Congress (CAC), (2018).

[11] Zhou, B. W., Littler, T., Wang, H. F., "The impact of vehicle-to-grid on electric power systems: A review", Proceedings of The 2nd IET Renewable Power Generation Conference (RPG 2013), (2013).

[12] Yilmaz, M., Krein, P. T., "Review of the impact of Vehicle-to-Grid technologies on distribution systems and utility interfaces", IEEE Transactions on Power Electronics, 28(12):5673, (2013).

[13] Esther, S., Singh, S., Goswami, A., Sinha, N., "Recent challenges in vehicle to grid integrated renewable energy system: A Review", Proceedings of The Second International Conference on Intelligent Computing and Control Systems (ICICCS), (2018). 
[14] Khosrojerdi, F., Taheri, S., Taheri, H., Pouresmaeil, E., "Integration of electric vehicles into a smart power grid: A technical review", Proceedings of The IEEE Electrical Power and Energy Conference (EPEC), (2016).

[15] Tan, K. M., Ramachandaramurthy, V. K., Yong, J. Y., "Integration of electric vehicles in smart grid: A review on vehicle to grid technologies and optimization techniques", Renewable and Sustainable Energy Reviews, 53:720, (2016).

[16] Mwasilu, F., Justo, J. J., Kim, E. K., Do, T. D., Jung, J. W., "Electric vehicles and smart grid interaction:A review on vehicle to grid and renewable energy sources integration", Renewable and Sustainable Energy Reviews, 34:501, (2013).

[17] Fard, A. K., Abbasi, A., Rostam, M.A., Khosravi, A., Optimal distribution feeder reconfiguration for increasing the penetration of plug-in electric vehicles and minimizing network costs", Energy, 93:1693, (2015).

[18] Santos, A. C., Rodriguez, C. P., Asensio E. R., Diez, D. B., "Estimating the benefits of vehicleto-home in islands: The case of the Canary Islands", Energy, 134:311, (2017).

[19] Pinto, J. G., Monteiro, V., Goncalves, H., Exposto, B., Pedrosa, D., Couto, C., Afonso, J. L., "Bidirectional battery charger with Grid-to-Vehicle, Vehicle-to-Grid and Vehicle-to-Home technologies", Proceedings of The 39th Annual Conference of the IEEE Industrial Electronics Society (IECON):5934, (2013).

[20] Wang, Z. P., Wang, S., "Grid power peak shaving and valley filling using Vehicle-to-Grid systems", IEEE Transactions on Power Delivery, 28(3):1822, (2013).

[21] Sun, Y., Liu, W., Su, M., Li, X., Wang H., Yang, J., "A unified modeling and control of a multifunctional current source-typed converter for V2G application", Electric Power Systems Research, 106:12, (2014).

[22] Monteiro, V., Pinto, J.G., Exposto, B., Goncalves, H., Ferreira, J.C., Couto, C., Afonso, J.L., "Assessment of a battery charger for electric vehicles with reactive power control", Proceedings of The 38th Annual Conference on IEEE Industrial Electronics Society (IECON 2012):5142, (2012).

[23] Gould, C., Colombage, K., Wang, J.B., Stone D., Foster, M., "A comparative study of on-board bidirectional chargers for electric vehicles to support Vehicle-to-Grid power transfer", Proceedings of The IEEE 10th International Conference on Power Electronics and Drive Systems (IEEE PEDS):639, (2013).

[24] Yin, S., Tseng, K. J., Tong, C. F., "A 99\% efficiency SiC three-phase inverter using synchronous rectification", Proceedings of The IEEE Applied Power Electronics Conference and Exposition (APEC), (2016).

[25] Lee, B.K., Kim, J.P., Kim, S.G., "An isolated/bidirectional PWM resonant converter for V2G(H) EV On-Board charger", IEEE Transactions on Vehicular Technology, 66(9):7741, (2017).

[26] Zahid, Z.U., Dalala, Z.M., Chen, R., "Design of bidirectional DC-DC resonant converter for Vehicle-to-Grid (V2G) applications", IEEE Transactions on Transportation Electrification, 1(3):232, (2015). 
[27] Sandoval, J.J., Essakiappan, S., Enjeti, P., "A bidirectional series resonant matrix converter topology for electric vehicle DC fast charging", Proceedings of The IEEE Applied Power Electronics Conference and Exposition (APEC), (2015).

[28] Wei, Y., Luo, Q., Du, X., Altin, N., Nasiri, A., Alonso, J. M., "A dual Half-bridge LLC resonant converter with magnetic control for battery charger application," IEEE Transactions on Power Electronics, 35(2):2196, (2020).

[29] Wei, Y., Luo, Q., Chen, S., Sun, P. and Altin, N., "Comparison among different analysis methodologies for LLC resonant converter", IET Power Electronics, 12(9):2236, (2019).

[30] Kan, J., Wu, Y., Tang, Y., "Dual active full-bridge bidirectional converter for V2G charger based on high-frequency AC buck-boost control strategy", Proceedings of The IEEE Conference and Expo Transportation Electrification Asia-Pacific (ITEC Asia-Pacific), (2016).

[31] Byen, B.J., Kang, K.P., Cho, Y., "A high-efficiency variable modulation strategy for a dual-activebridge converter with a wide operating range", Proceedings of The 9th International Conference on Power Electronics and ECCE Asia (ICPE-ECCE Asia), (2015).

[32] Ozdemir, S., Balci, S., Altin, N., Sefa, I., "Design and performance analysis of the three-level isolated DC-DC converter with the nanocyrstalline core transformer", International Journal of Hydrogen Energy, 42(28):17801, (2017).

[33] Varajao, D., Araujo, R. E., Miranda, L.M., Lopes, J.P., Weise, N. D., "Control of an isolated single-phase bidirectional AC-DC matrix converter for V2G applications", Electric Power Systems Research, 149:19, (2017).

[34] Thomas, P., Chacko, F.M., "Electric vehicle integration to distribution grid ensuring quality power exchange", Proceedings of The International Conference on Power Signals Control and Computations (EPSCICON), (2014).

[35] Zgheib, R., Al-Haddad, K., Kamwa, I., "V2G, G2V and active filter operation of a bidirectional battery charger for electric vehicles", Proceedings of The IEEE International Conference on Industrial Technology (ICIT), (2016).

[36] Rodrigues, M.C.B.P., Souza, I.D.N., Ferreira, A.A., "Simultaneous active power filter and G2V (or V2G) operation of EV on-board power electronics", Proceedings of The 39th Annual Conference of the IEEE Industrial Electronics Society (IECON), (2013).

[37] Tabatabaee, S., Mortazavi, S. S., Niknam, T., "Stochastic scheduling of local distribution systems considering high penetration of plug-in electric vehicles and renewable energy sources", Energy, 121:480, (2017).

[38] Ruiz, J.R., Ruiz, J.P., Martin, S., Aguado, J. A., De La Torre, S., "Probabilistic congestion management using EVs in a smart grid with intermittent renewable generation", Electric Power Systems Research, 137:155, (2016).

[39] Mozafar, M.R, Amini, M. H., Moradi, M. H., "Innovative appraisement of smart grid operation considering large-scale integration of electric vehicles enabling V2G and G2Vsystems", Electric Power Systems Research, 154:245, (2018).

[40] Brenna, M., Foiadelli, F., Longo, M., Zaninelli, D., "Power quality improvement in primary distribution grids through vehicle-to-grid technologies", Proceedings of The IEEE International Electric Vehicle Conference (IEVC): 1-8, (2014). 
[41] Wang, D., Coignard, J., Zang, T., Zhang, C., Saxena, S., "Quantifying electric vehicle battery degradation vs. vehicle-to-grid services", Journal of Power Sources, 332:193, 2016.

[42] Dubarry, M., Devie, A., McKenzie, K., "Durability and reliability of electric vehicle batteries under electric utility grid operations: Bidirectional charging impact analysis", Journal of Power Sources, 358:39, (2017).

[43] Amoroso, F.A., Cappuccino, G., "Advantages of efficiency-aware smart charging strategies for PEVs", Energy Conversion and Management, 54(1):1, 2012.

[44] Sarabi, S., Davigny, A., Courtecuisse, V., Riffonneau, Y., Robyns, B., "Potential of vehicle-togrid ancillary services considering the uncertainties in plug-in electric vehicle availability and service/localization limitations in distribution grids", Applied Energy, 171:523, (2016).

[45] Singh, M., Kumar, P., Kar, I., "A real-time smart charging station for EVs designed for V2G scenario and its coordination with renewable energy sources", Proceedings of The IEEE Conference on Power and Energy Society General Meeting (PESGM), (2016).

[46] Mahmud, K., Morsalin, S., Kafle, Y. R., "Improved peak shaving in grid-connected domestic power systems combining photovoltaic generation, battery storage, and V2G-capable electric vehicle", Proceedings of The IEEE International Conference on Power System Technology (POWERCON), (2016).

[47] Ghofrani, M., Arabali, A., Ghayekhloo, M., "Optimal charging/discharging of grid-enabled electric vehicles for predictability enhancement of PV generation", Electric Power Systems Research, 117, 134, (2014).

[48] Luo, Y., Shi, Y., Zheng, Y., Gang, Z., Cai, N., "Mutual information for evaluating renewable power penetration impacts in a distributed generation system", Energy, 141:290, 2017.

[49] Qiu, L. Q., Lin, Y., Lin, H. Y., Lin, Z. S., Lin, F., "Research on smart charging and discharging decision model of electric vehicle based on energy router", Proceedings of The IEEE Conference on Energy Internet and Energy System Integration (EI2), (2017).

[50] Yuan, K., Sun, C., Song, Y., "Electric vehicle smart charging network under the energy internet framework", Proceedings of The IEEE Conference on Energy Internet and Energy System Integration (EI2), (2017).

[51] Lund, H., Østergaard, P. A., Connolly, D., Mathiesen, B. V., "Smart energy and smart systems", Energy, 137:556, (2017).

[52] Bhatt, J., Shah, V., Jani, O., "An instrumentation engineer's review on smart grid: Critical applications and parameters", Renewable \& Sustainable Energy Reviews, 40:1217, (2014).

[53] Honarmand, M., Zakariazadeh, A., Jadid, S., "Optimal scheduling of electric vehicles in an intelligent parking lot considering vehicle-to-grid concept and battery condition", Energy, 65:572, (2014).

[54] Nasrallah, Y., Al-Anbagi, Y.I., Mouftah, H. T., "Mobility impact on the performance of electric vehicle-to-grid communications in smart grid environment", Proceedings of The IEEE Symposium on Computers and Communication (ISCC), (2015).

[55] Chaudhry, H., Bohn, T., "Security concerns of a plug-in vehicle", Proceedings of The IEEE PES Innovative Smart Grid Technologies (ISGT), (2012). 
[56] Zhang, Y., Gjessing, S., Liu, H., "Securing vehicle-to-grid communications in the smart grid", IEEE Wireless Communications, 20(6):66, (2013).

[57] Yuan, Z., Xu, H., Han, H., "Research of bi-directional smart metering system for EV charging station based on ZigBee communication", Proceedings of The IEEE Conference and Expo on Transportation Electrification Asia-Pacific (ITEC Asia-Pacific), (2014).

[58] Yuan, Z., Xu, H., Han, H., "Research of smart charging management system for Electric Vehicles based on wireless communication networks" Proceedings of The IEEE 6th International Conference on Information and Automation for Sustainability (ICIAfS), (2012).

[59] Han, W., Xiao, Y., "Privacy preservation for V2G networks in smart grid: A survey", Computer Communications, 91-92:17, (2016).

[60] Au, M. H., Liu, J. K., "A new payment system for enhancing location privacy of electric vehicles", IEEE Transactions on Vehicular Technology, 63(1):3, (2014).

[61] Abdallah, A., Shen, X., "Lightweight security and privacy-preserving scheme for V2G connection", Proceedings of The IEEE Global Communications Conference (GLOBECOM), (2015).

[62] Zhang, S., Li, Q., Wu, J., "A security mechanism for software-defined networking based communications in vehicle-to-grid", Proceedings of The IEEE Smart Energy Grid Engineering (SEGE), (2016).

[63] Ghosh, D. P., Thomas, R. J., Wicker, S. B., "A Privacy-Aware design for the Vehicle-to-Grid framework", Proceedings of The 46th Hawaii International Conference on System Sciences (HICSS), (2013).

[64] Liu, H., Ning, H. Zhang, Y., "Role-Dependent privacy preservation for secure V2G networks in the smart grid", IEEE Transactions on Information Forensics and Security, 9(2):208, (2014).

[65] Hosseini, S.S., Badri, A., Parvania, M., "A survey on mobile energy storage systems (MESS): Applications, challenges and solutions", Renewable \& Sustainable Energy Reviews, 40:161, (2014).

[66] Hosseini, S.S., Badri, A., Parvania, M., "Smart parking lot to minimize residential grid losses based on customer priorities", Proceedings of The International Conference on Power, Energy and Control (ICPEC): 728, (2013).

[67] Hutson, C., Venayagamoorthy, G.K., Corzine, K.A., "Intelligent scheduling of hybrid and electric vehicle storage capacity in a parking lot for profit maximization in grid power transactions", Proceedings of The IEEE Energy 2030 Conference: 432, (2008).

[68] Kuran, M.S., Viana, A.C., Iannone, L., Kofman, D., Mermoud, G., Vasseur, J.P., "A smart parking lot management system for scheduling the recharging of electric vehicles", IEEE Transactions on Smart Grid, 6(6):2942, (2015).

[69] Lede, A. M. R., Molina, M.G., Martinez, M., "Microgrid architectures for distributed generation: A brief review", Proceedings of The Innovative Smart Grid Technologies Conference - Latin America (ISGT Latin America), (2017).

[70] Han, S., Han, S., "Development of short-term reliability criterion for frequency regulation under high penetration of wind power with vehicle-to-grid support", Electric Power Systems Research, 107:258, (2014). 
[71] Musio, M., Porru, M., Serpi, A., Marongiu, I., Damiano, A., "Optimal electric vehicle charging strategy for energy management in microgrids", Proceedings of The IEEE International Electric Vehicle Conference (IEVC), (2014).

[72] Kavousi-Fard, A., Abunasri, A., Zare, A., Hoseinzadeh, R., "Impact of plug-in hybrid electric vehicles charging demand on the optimal energy management of renewable micro-grids", Energy, 78:904, (2014).

[73] Waqar, A., Wang, S., Khalid, M. S., Shi, X., "Multi-objective chance constrained programming model for operational-planning of V2G integrated microgrid", Proceedings of The 5th International Conference on Electric Utility Deregulation and Restructuring and Power Technologies (DRPT), (2015).

[74] Wang, Y., Wang, B., Zhang, T., Nazaripouya, H., Chu, C. C., Gadh, R., "Optimal energy management for Microgrid with stationary and mobile storages", Proceedings of The IEEE/PES Transmission and Distribution Conference and Exposition (T\&D), (2016).

[75] Mortaz, E., Valenzuela, J., "Optimizing the size of a V2G parking deck in a microgrid", International Journal of Electrical Power \& Energy Systems, 97:28, (2018).

[76] Fossati, J. P., Galarza, A., Villate, A. M., Fontán, L., "A method for optimal sizing energy storage systems for microgrids", Renewable Energy, 77:539, (2015).

[77] Khooban, M. H., Niknam, T., Shasadeghi, M., "Load frequency control in microgrids based on a stochastic noninteger controller", IEEE Transactions on Sustainable Energy, 9:863, (2017).

[78] ur Rehman, U., Riaz, M., "Vehicle to grid system for load and frequency management in smart grid", Proceedings of The International Conference on Open Source Systems \& Technologies (ICOSST), (2017).

[79] Hassan, M., Niknam, K. T., Blaabjerg, F., Dragičević, T., "A new load frequency control strategy for micro-grids with considering electrical vehicles", Electric Power Systems Research, 143:585, (2017).

[80] Morris C., University of Delaware to offer BMW Mini-E EVs for lease in V2G project. Charged Electric Vehicles Magazine. [Online]. Available: https://chargedevs.com/newswire/universitydelaware-to-offer-bmw-mini-e-evs-for-lease-in-v2g-project/, (2014, June).

[81] Ayre, J., Nissan Testing LEAFs In Energy Supply \& Demand Management Systems. Clean Technica. [Online]. Available: http://cleantechnica.com/2014/10/28/nissan-testing-use-leaf-evsenergy-supply-demand-management-systems/, (2014, Oct.).

[82] Ayre, J., State fact sheets on household energy use. U.S Energy Information Administration. [Online]. Available: http://www.eia.gov/consumption/residential/, (2013, Aug.).

[83] Gearhart, C., Gonder, J., Markel, T., "Connectivity and convergence: Transportation for the 21st century", IEEE Electrification Magazine, 2(2):6, (2014).

[84] Sortomme, E., El-Sharkawi, M.A., "Optimal combined bidding of Vehicle-to-Grid ancillary services", IEEE Transactions on Smart Grid, 3(1):70, 2012. 